\title{
CHANGES IN THE STRUCTURE OF ASSEMBLAGES OF THREE LIOLAEMUS LIZARDS (IGUANIA, LIOLAEMIDAE) IN A PROTECTED AREA OF SOUTH-CENTRAL CHILE AFFECTED BY A MIXED-SEVERITY WILDFIRE
}

\author{
Alfredo H. Zúñiga \\ Laboratorio de Ecología, Universidad de Los Lagos, Osorno, Chile \\ E-mail:zundusicyon@gmail.com
}

A. H. Zúñiga (https://orcid.org/0000-0002-0504-7540)

\begin{abstract}
Changes in the Structure of Assemblages of Three Liolaemus lizards (Iguania, Liolaemidae) in a Protected Area of South-Central Chile Affected by a Mixed-Severity Wildfire. Zúñiga, A. H. - The use of space by sympatric lizards was assessed in a protected area in south central Chile that was affected by a wildfire three years prior. I did systematic monitoring in plots with varying degrees of wildfire severity. There I counted the frequency of recordings of each species, and I considered four treatments (low severity, medium severity, high severity and unburned control). Additionally, I subdivided these four into three different microhabitats (ground, trunks and trees). The microhabitats were differentiated by the level of damage caused to vegetation as a consequence of the wildfire. Three species were recorded, slender lizard, Liolaemus tenuis (Duméril \& Bibron, 1837), orange-bellied lizard, Liolaemus pictus (Duméril \& Bibron, 1837), and elegant tree iguana, Liolaemus lemniscatus (Gravenhorst, 1837). It was revealed that the presence of Liolaemus tenuis was linked to sites with less fire damage; the species disappeared in high severity sites. In contrast, $L$. pictus displayed a more generalist use of microhabitats, with a similar presence in the different treatments. On the other hand, L. lemniscatus showed a predominant use of the ground, which became more evident in the most severe sites. The pattern found are discussed, as well the influence of fire in reshaping environments.
\end{abstract}

Key words: assemblage, microhabitat, overlap, severity, space use.

\section{Introduction}

Disturbances are events that affecting the physical conditions of an ecosystem causing biomass remotion and functionality in ecosystems (Pickett \& White, 1985). Within the ways these events manifest, wildfires are a type of disturbance of special relevance, due to the great removal of vegetation that generates in compare with others (Bond \& Keeley, 2005). This produces a loss of resources, both in terms of food and shelter, affecting animal communities, namely sets of species that coexist at local and temporal scale (Morin, 2011). Within 
this organizational level, assemblies are sets of species with taxonomic affinity (Jaksic, 2000), whose similarity allows its analysis for ecological studies. Although the response of wildlife to fire has been studied in various taxa (Dellasala \& Hanson, 2015), in the particular case of reptiles, due to their low vagility (Ramírez-Bautista \& Cruz-Elizalde, 2013), which could limit the possibility to colonize new patches of habitat under situations of disturbance affecting their persistance. This fact is especially important due to the fact that vegetation favours differentiation between species in the use of microhabitats (Pianka, 1973; Simbtowe, 1984). By other hand, fire may favour a group of species, with low requirements of plant cover (Sutton et al., 2014), which evidences the variability of responses in an assembly. There are reports of high vulnerability of species to habitat loss and fragmentation (Beirne et al., 2013; Maynard et al., 2016), which affects its persistence at local level. There is evidence indicating that the impact of fire can cause effects on reptile assemblies in semi-arid ecosystems (Bradstock \& Cohn, 2002; Nimmo et al., 2012), Mediterranean forests (Ferreira et al., 2016), and grazed savannas (Woinarski et al., 1999). However, there are informative gaps regarding its effect on other environments, such as the temperate forest of southern Chile. This ecosystem has been characterized by presenting varied regimes of fire by natural causes through centennials (Fletcher \& Moreno, 2012), with changes in vegetation. Therefore, it is suggested that the local fauna, especially those with low vagility, would have a low capacity to this type of disturbance.

Liolaemidae is a family of Iguanian lizards, which includes three genus, Liolaemus, Phymaturus and Ctenoblepharys (Pianka \& Witt, 2003). In this family, Liolaemus is a highly diverse South American genus ( 276 spp., Uetz et al., 2020). In a north-south sense, these lizards are distributed from Peru to South extreme of Argentina and Chile (Donoso-Barros 1966) probably as consequence of the great morphological and physiological plasticity of this group (Labra et al., 2009), which could explain its high diversity throughout this territory. This fact is associated, to a large degree, with its morphological particularities which, in addition to determining the way of displacement, allows its differentiation among species along the vertical axis of space (Schulte et al., 2004; Tulli et al., 2011). In this way, the partition in the use of space between species is possible (Medel et al., 1988), which is based on the assumption of environmental heterogeneity of space, where different microhabitats are present. However, a fire event would eliminate much of this spatial arrangement, affecting the availability of microhabitats, with the consequent restriction on species with spatial specialization. This could result in a restructuring of the assembly, which is especially important for animal conservation. Although there is background about the spatial ecology of species of this family affected by fire produced by volcanic activity (Mora \& Labra, 2017), there is no background about the role of fire as a configurator of Liolaemus assemblies, which is a critical issue due to the increasing risk of occurrence of these events as a result of human activities (Altamirano et al., 2013).

The objective of this work is to characterize the use of microhabitats by sympatric lizards of the genus Liolaemus, in a protected area in southern-central Chile (Zúniga et al., 2020). Through the comparison of the frequencies of the use of space in plots with different degrees of fire severity, I test the hypothesis that the severity of fire will result in changes both in the conformation of assemblies, and in the co-use of microhabitats by the species, as a consequence of environmental changes produced.

\section{Material and methods}

China Muerta National Reserve $\left(38^{\circ} 42^{\prime} 00^{\prime \prime} \mathrm{S}, 71^{\circ} 26^{\prime} 00^{\prime \prime} \mathrm{W}\right)$ is a protected area of southern-central Chile, located in the piedmont range zone. This reserve has an area of $11368 \mathrm{ha}$, and is characterized by presenting forest formations of araucaria (Araucaria araucana), associated with trees of the Nothofagus genus (CONAF, 2014), in altitudes that fluctuate between 1550 and 1995 masl. It has a mediterranean-humid climate, with seasonal variations consisting of drought in summer and snow in winter (Köeppen, 1948). In March 2015, this reserve suffered a fire that covered approximately 3100 ha, affecting vegetation in different categories of severity. Severity categories were determined on the level of damage in soil, herbs, shrubs and trees (CONAF, 2015). In this way, a low severity level was established where there was a superficial burn of the vegetation, without root damage; a medium severity level, where there was partial burning on canopy and roots, and partial root damage; and a high severity level, where there was almost total bush burning, with considerable tree damage, in the form of carbonization (CONAF, 2015) (fig. 1).

Between December 2017 and April 2018, monitoring activities were carried out in the study area for detection of lizards, through plots of 0.4 ha (Uribe \& Estades, 2014), through three treatments (low, medium and high levels of damage severity), plus a control (unburned sites), during morning hours once every two weeks. Each treatment had a patch which acts as a replica, those who had an average distance greater than $200 \mathrm{~m}$ from each other. The observed frequencies were considered as an indicator of the habitat use of each species (Zúñiga et al., 2016). The diversity in each treatment was estimated through the Shannon index (Shannon, 1948) and evenness associated (Morin, 2011). The resulting statistical significance between treatment comparisons was obtained through Hutchenson procedure (Hutchenson, 1970). To decrease the probability of incur in type I-error, I performed Bonferroni's multiple comparisons (Holm, 1979), considering these P-values of $0.05 / 6=0.0083$ for significance. To determine the effect of treatments on the abundance of recordings of species, analyses of Kruskal-Wallis was performed (Sokal \& Rohlf, 1995). 


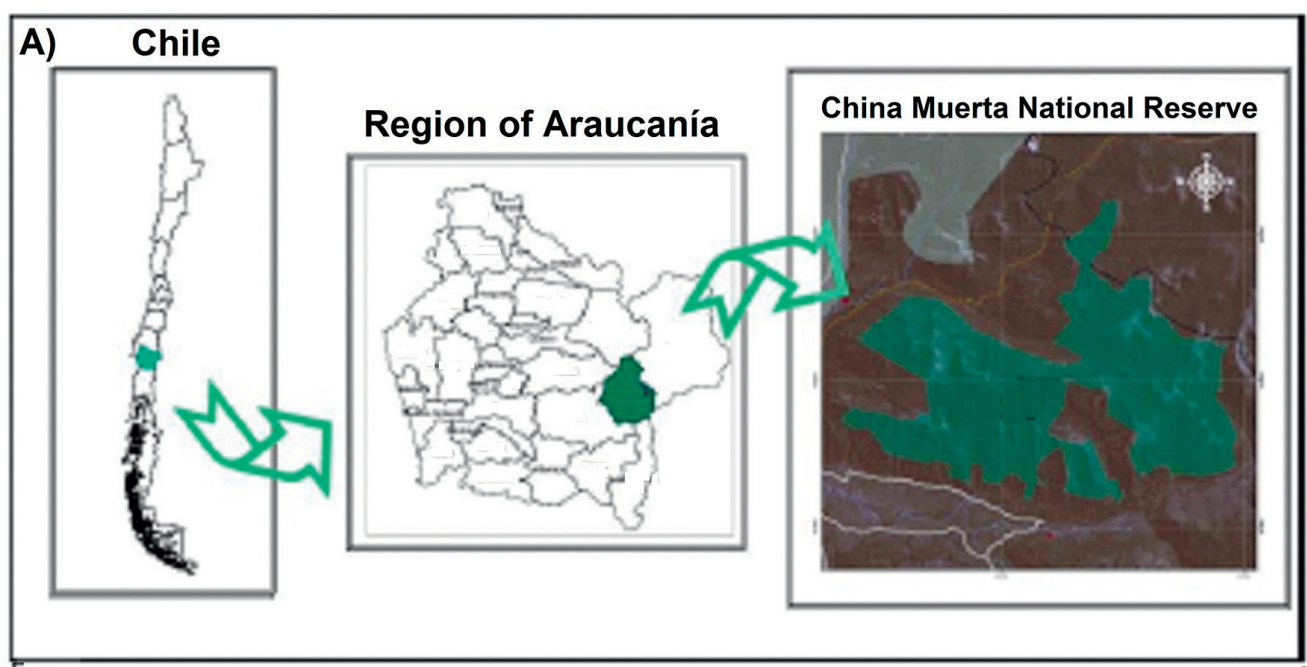

B)

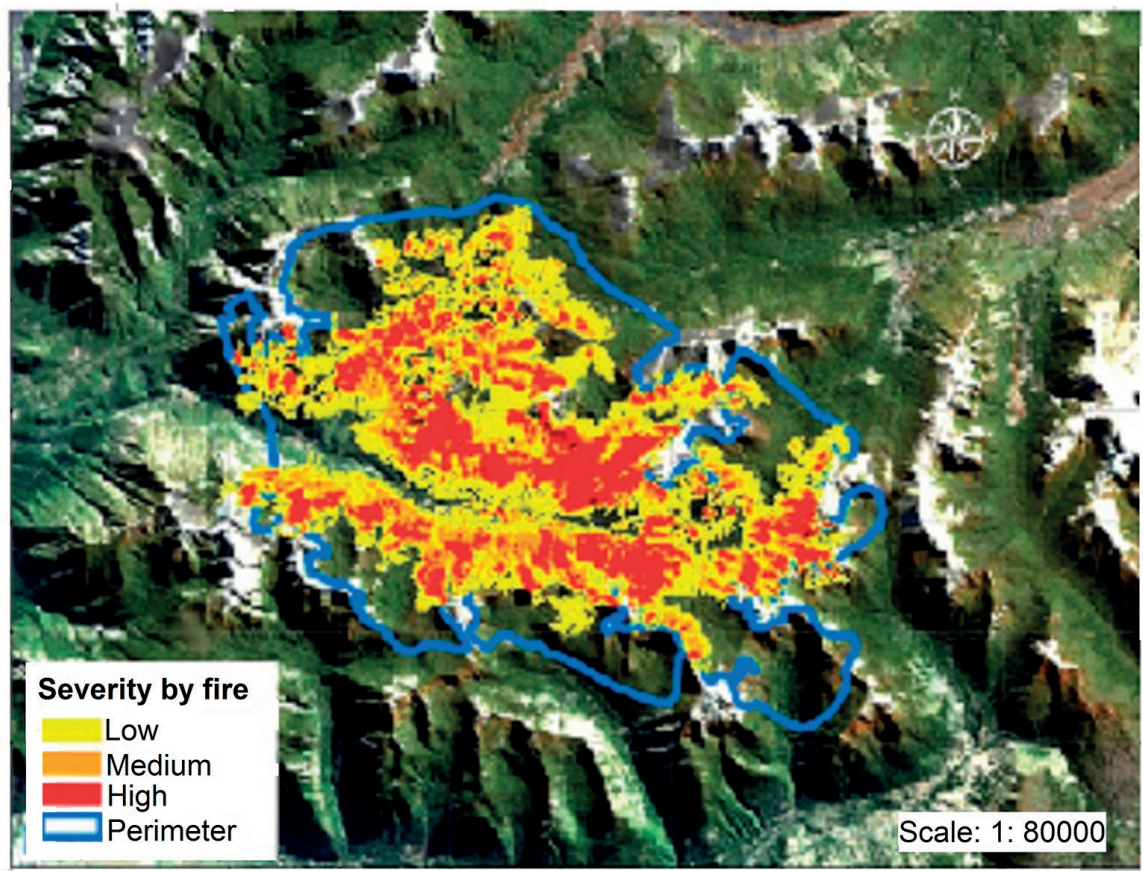

Fig. 1. Study area: A - Geographical context; B - Mosaic of areas of different degrees of severity (modified from CONAF, 2014, 2015).

Each treatment was subdivided in three specific microhabitats, which allowed estimate its relative use by lizards (Medel et al., 1988). These microhabitats consisted of trees, logs and ground. The niche amplitude for each species and each treatment was estimated through the Levins index (Levins, 1968), which considered the proportion of use of microhabitats. The standard deviation of this index was obtained through jackknife procedure (Jaksic \& Medel, 1987). The overlap in the use of microhabitats by lizards was estimated using the Pianka index (Pianka, 1973), which value fluctuates between 0 (no overlap) and 1 (full overlap). The statistical significance for each pairwise comparison was obtained by Hutchenson procedure (Hutchenson, 1970). Additionally, cover of canopy, shrub and herbaceous vegetation, leaf litter, dead wood and number of fallen logs in random plots of $100 \mathrm{~m}^{2}$ was estimated through the treatments and control (40 points for each case). These values were compared with the abundance of recordings the species obtained through a correlation analysis (Quinn \& Keough, 2002), to determine the variables of greater association with recordings of lizards. All these analyses were performed with XLSTAT 3.02 trial version. 


\section{Results}

A total of 480 records were obtained, where three species were found: Liolaemus tenuis Duméril \& Bibron, 1837, L. pictus (Duméril \& Bibron, 1837) and L. lemniscatus Gravenhorst, 1837 (fig. 2). These species showed different abundance of recordings in the treatments, which were reflected in their respective diversity patterns (table 1), distinguishing a high evenness in control low severity and high severity treatments, while there was a lower richness of species in high severity treatments. When the diversity of the treatments was compared in a paired way, significant differences were obtained in four cases, three of these were associated with control $(\mathrm{T}=6.69,4.59,5.65$ control vs. low, medium and high severity, respectively; $\mathrm{p}<0.0001$ in all cases), and low severity vs. medium severity treatments $(T=2.62, p=0.0164)$.

Regarding the effect of the treatments on the abundance of recordings of species, it was observed that all species showed differences in those terms, where L. tenuis was absent in the high severity treatment (Kruskal-Wallis test, $\mathrm{H}=20.996, \mathrm{p}<0.0001$, d.f.: 2). The rest of the species, although they were present in all treatments, also differed in their abundance of recordings $(\mathrm{H}=16.348, \mathrm{p}=0.001 ; \mathrm{H}=8.993, \mathrm{p}=0.03$ for L. pictus and L. lemniscatus, respectively; g.l.: 3 in all cases). The use of microhabitats varied through species and treatments (fig. 3), which can be reflected in their respective niche amplitudes (table 2), with a declining trend as the severity increased. In the control, although the three species used the three microhabitats, L. tenuis stood out for its predominant use of trees, while the other two species were more linked to the use of logs and ground. In the case of low severity treatment, it was observed that both L. pictus and L. lemniscatus used all three types of microhabitat, while L. tenuis was absent on the ground. It was observed that the effect of treatments showed different patterns of microhabitat use, as was the case for L. pictus (Kruskal-Wallis test, $\mathrm{H}=13.831, \mathrm{p}=0.001 ; \mathrm{H}=7.864, \mathrm{p}=0.020 ; \mathrm{H}=19.557, \mathrm{p}<0.0001$ for control, low severity and medium severity treatments, respectively; use of trees were lesser than the other microhabitats, Tukey test, $\mathrm{p}<0.05$ ), and high severity treatment (Mann-

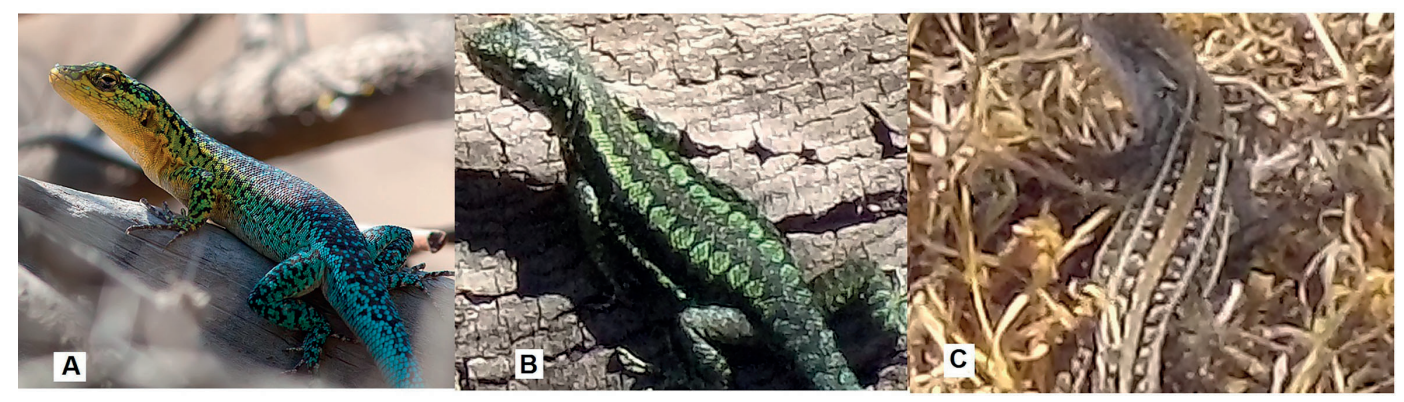

Fig. 2. Species of Liolaemus lizards recorded in the study area. A - L. tenuis (@ G. Zúñiga); B - L. pictus (c) A. H. Zúñiga); C - L. lemniscatus ( A. H. Zúñiga).

Table 1. Number of recordings obtained for each species (SD), diversity ( $\left.H^{\prime}\right)$, maximum diversity $\left(H^{\prime} \max \right)$ and evenness $\left(J^{\prime}\right)$ in each treatment, through the study area.

\begin{tabular}{l|c|c|c|c}
\hline \multicolumn{1}{c}{ Species } & Control & Low severity & Medium severity & High severity \\
\hline L. tenuis & $40(1.05)$ & $24(0.66)$ & $6(0.35)$ & $0(0)$ \\
L. pictus & $60(0.99)$ & $42(0.82)$ & $58(0.85)$ & $54(1.11)$ \\
L. lemniscatus & $54(0.91)$ & $40(1.08)$ & $58(1.18)$ & $50(1.07)$ \\
$\mathrm{H}^{\prime}$ & 1.08 & 1.07 & 0.86 & 0.69 \\
$\mathrm{H}^{\prime} \max$ & 1.098 & 1.098 & 1.098 & 0.693 \\
$\mathrm{~J}^{\prime}$ & 0.98 & 0.97 & 0.78 & 0.99 \\
\hline
\end{tabular}




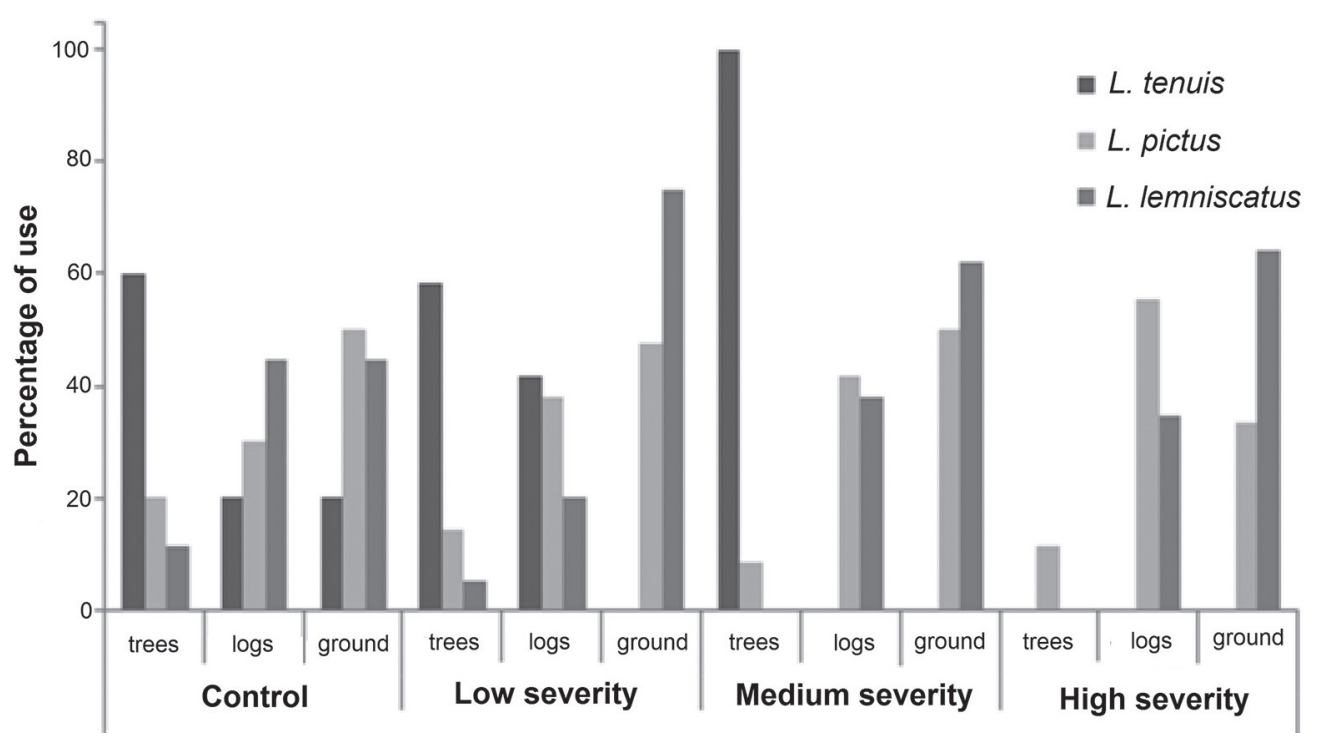

Fig. 3. Percentages of microhabitat use by lizards in study area according to severity of damage caused by fire.

Table 2. Breadth niche indexes (SD) by Liolaemus lizards in the study area, through the control and the different treatments

\begin{tabular}{l|c|c|c|c}
\hline \multicolumn{1}{c|}{ Species } & Control & Low severity & Medium severity & High severity \\
\hline L. tenuis & $2.27(5.57)$ & $1.94(1.97)$ & 1 & - \\
L. pictus & $2.63(2.36)$ & $2.54(1.62)$ & $2.32(1.62)$ & $2.32(2.77)$ \\
L. lemniscatus & $2.45(1.31)$ & $1.65(10.91)$ & $1.88(0.86)$ & $1.85(3.22)$ \\
\hline
\end{tabular}

Whitney test, $\mathrm{U}=148, \mathrm{p}=0.001$, only logs and ground microhabitats), where higher use for logs was observed. For L. lemniscatus a similar pattern was observed $(\mathrm{H}=17.816, \mathrm{p}<0.0001$; $\mathrm{H}=24.740, \mathrm{p}<0.0001 ; \mathrm{U}=18 ; \mathrm{p}<0.0001$ to control, low severity and medium severity treatments; use of trees were lesser than the other microhabitats, Tukey test, $\mathrm{p}<0.05$ ), and high severity $(U=30, p=0.003)$, where higher use for ground was observed. In the case of $L$. tenuis, although significant differences were observed in the control $(\mathrm{H}=7.091$, $\mathrm{p}=0.030$; use of the trees was higher than the other microhabitats, Tukey test, $\mathrm{p}<0.05)$, it did not obtain a similar pattern in the low severity treatment $(U=99.5, p=0.386)$ while in medium severity only trees were used.

Regarding the overlap of the use of microhabitats, it was observed that L. tenuis had intermediate values with L. pictus, and low values with L. lemniscatus, which were decreasing as severity of treatment increased, showing significant differences in all cases (table 3). On the other hand, L. pictus showed a high overlap with L. lemniscatus, where no statistical significance was observed in any of the pairwise comparisons.

Table 3. Overlap in the use of microhabitats for each treatment in the study area. Under the shaded lines the statistical significance from the paired comparisons is shown (C - Control; LS - Low severity; MS - Medium severity; HS - High severity).

\begin{tabular}{|c|c|c|c|c|c|c|c|c|c|c|c|c|}
\hline & \multicolumn{4}{|c|}{ L. tenuis } & \multicolumn{4}{|c|}{ L. pictus } & \multicolumn{4}{|c|}{ L. lemniscatus } \\
\hline & $\mathrm{C}$ & LS & MS & HS & $\mathrm{C}$ & LS & MS & HS & $\mathrm{C}$ & LS & MS & HS \\
\hline L. tenuis & & & & & 0.68 & 0.53 & 0.78 & - & 0.57 & 0.20 & 0 & - \\
\hline L. pictus & 0.001 & 0.001 & $<0.0001$ & - & & & & & 0.96 & 0.90 & 0.69 & 0.85 \\
\hline L. lemniscatus & 0.016 & 0.001 & $<0.0001$ & - & 0.364 & 0.873 & 0.063 & 0.491 & & & & \\
\hline
\end{tabular}


Table 4. Spearman correlations ( $\rho)$ obtained for the species of the study area in relation to vegetation cover

\begin{tabular}{l|c|c|c|c|c|c}
\hline \multicolumn{1}{c|}{ Species } & canopy & herbs & shrubs & litter & dead wood & trunks \\
\hline L. tenuis & 0.542 & 0.303 & 0,664 & 0.595 & -0.511 & -0.424 \\
L. pictus & -0.261 & 0.211 & -0.034 & -0.338 & 0.171 & 0.190 \\
L. lemniscatus & -0.187 & 0.270 & -0.319 & -0.223 & 0.223 & 0.325 \\
\hline
\end{tabular}

Regarding the effect of vegetation cover on the abundance of recordings of species, it was observed that L. tenuis had relation in different directions, being positive for the first four variables (canopy, herbs, shrubs and litter; table 4), and negative for the last two (dead wood, trunks), being significative in all cases $(\mathrm{p}<0.0001)$. In the case of L. pictus, a low correlation was obtained for these varaibles, being significant only for litter $(\mathrm{p}=0.012)$. For $L$. lemniscatus, statistical significance was observed for herbaceous vegetation $(\mathrm{p}=0.048)$, shrub vegetation $(\mathrm{p}=0.018)$, and number of $\operatorname{logs}(\mathrm{p}=0.015)$. All coverage showed significant differences between treatments $(\mathrm{H}=21.235, \mathrm{H}=22.274$, $\mathrm{H}=32.098, \mathrm{H}=31.912, \mathrm{H}=33.218, \mathrm{H}=32.369$ for canopy, herbs, shrubs, litter, dead wood and trunks, respectively; $\mathrm{p}<0.0001$ in all cases; d.f. $=3$ ).

\section{Discussion}

The differences observed in the composition of lizard assemblies in the study area, account for the relative sensitivities of each species with respect to the severity of fire damage, with changes both at the level of the treatments and frequency of use of microhabitats. This fact evidences the relative sensibility of species to changes in the cover of microhabitats produced by fire. As a consequence, it would take place changes in the structure of assemblages, fact observed through pairwise comparisons among treatments. The most critical case was L. tenuis, which showed a progressive decrease in its recordings when severity increased, until its disappearance in the most severe. L. tenuis is a mainly arboreal habits species (Schulte et al., 2004) and its occurrence would be more limited in the sites of greater severity, mainly in high severity, due to the great loss of trees by fire (CONAF, 2015), affecting the availability of required microhabitats. The high value in the standard deviation in the niche breadth index for control, allow visualize the absence in the lower strata, which evidences a low use of the ground. This is consistent with its positive relationship with tree canopy, being its highest frequency of recordings in the control and in the treatment of low severity. In the most severe sites, this coverage was lower, added to the low numbers of trees standing (CONAF, 2015), and located in a disperse way, limiting the dispersion of individuals. Additionally, since the diet of L. tenuis are associated with the consumption of insects (Hurtubia et al., 1973), it is assumed that fire would have a negative effect on this type of prey in the arboreal canopy, which constitutes a conspicuous group for this coverage (Arias et al., 2008), therefore it would depend on the sanitary state of the trees for its occurrence.

In the case of L. pictus, although it is recognized as a tree user (Schulte et al., 2004), eventually this lizard could use lower strata, such as logs and ground (Zúñiga et al., 2016), which suggests an ecological flexibility in the use of microhabitats according to their availability. This situation became evident in the most severe treatments, where the relative use of microhabitats changed, minimizing the occupation of trees. While this species has been recognized as insectivorous (Ortiz, 1974), eventually it can behave as omnivorous (Willson et al., 1995, 1996), which would facilitate foraging activities in high severity treatments, considering the floristic diversity present in these patches (UrrutiaEstrada et al., 2018). A remarkable fact is the absence of statistical significance in almost 
all microhabitat variables, which suggests a generalist profile in the use of treatments. Thus, the low variation in the niche breadth throughout the treatments demonstrates its flexibility in the use of space. The decrease in the use of trees in high severity treatment would be a consequence of the alteration in the spatial configuration, in which the availability of standing trees was lower.

The predominant use of ground by L. lemniscatus is consistent with previous reports (Schulte et al., 2004), despite its occasional incursions to trees and logs, which would not affect its occurrence in treatments of high severity. Similarly to L. tenuis, L. lemniscatus bases its diet mainly in insects (Hurtubia, 1973). However, this species may feed on those ground available prey (Elgueta, 1993), making fewer incursions in upper stratum, and consequently, minimizing the interaction with other species. In this sense, is it important to highlight the occurrence of specialized arthropods on substrates exposed to fire (Wikars, 2002), which could imply an additional feeding resource for lizards. This fact would be inferred about its positive correlation with dead wood, which would be linked to the presence of arthropods associated with this environment (Seibold et al., 2016).

The differences in the use of microhabitats by lizards across treatments suggest the existence of mechanisms of interference, resulting in the displacement of species to sites with different available resources (Pianka, 1973; Morin, 2011). In the case of L. tenuis, the overlap observed in relation to L. pictus is associated with the shared use of trees, suggesting that the latter species would be restricted for its access. Although there are records of aggressive reactions of $L$. tenuis against conspecifics (Manzur \& Fuentes, 1979), it would be expected that this species shows a similar behavior against L. pictus at the behest of its territorial character. By minimizing L. tenuis' presence in the most severe treatments, a competitive relaxation is generated that would result in a greater niche overlap by the two species of Liolaemus present. On the other hand, the low overlap of L. tenuis with L. lemniscatus suggests a great dissimilarity in the use of microhabitats, a fact that has been reported in commercial plantations in the intermediate depression of southerncentral Chile (Zúñiga et al., 2016). Thus, although in conditions without fire both species apparently would not show a great potential for interaction, the effect of severity results in a decrease in the degree of overlap between both species due to the specialist profile of L. tenuis, favoring L. lemniscatus for the use of available microhabitats.

Regarding the overlap in the use of microhabitats between L. pictus and L. lemniscatus, it is observed that these in general terms are very high, which would imply a high potential for competition. However, the similarity in abundance of recordings between both lizards suggests the absence of interference mechanisms. This fact is manifested sinceit was observed an absence of statistical significance among microhabitats use in all treatments, which evidences similar use of space by both species. Coexistence could be partially explained by the aforementioned food differentiation of both species, limiting the probability of competition of this type of resource (Bergallo \& Rocha, 1994). On the other hand, the high presence of fallen trunks in the most severe treatments gives it an additional spatial niche, a fact that to being manifested in a high proportion of use of this microhabitat, is assumed as a resource that would not be limiting. Another issue to highlight is the decrease in the value of overlap between two species of lizards in the treatment of medium severity, where $L$. tenuis had a minimal representation, suggesting that this latter species would act indirectly on interactions of remaining lizards (Morin, 2011), resulting in a relaxation in the their dynamics of competition. However, increasing of overlap in these species in the high severity treatment, where only two species are found, suggests that environmental factors would be modulating this interaction.

In conclusion, it can be found that fire has been a restrictive factor for species with arboreal habits, with a decrease of its abundance of recordings as the severity becomes greater, to be later absent in the most severe treatment. On the other hand, ecological differentiation would be a factor that minimizes negative interactions under adverse 
conditions, mainly in those generalist species. Although the pattern observed showed a structuring based on the available microhabitats accommodating the highly generalist lizard genus of Liolaemus, this scenario corresponds only to a temporal window in the post-fire recovery process in the study area.Therefore, systematic monitoring are necessary to determine changes in assembly structure (Pelegrin \& Bucher, 2010), as vegetation recovers from the disturbance.

I would like to express my thanks to Fondecyt Project No. 11150487; to Gustavo Zúñiga, for facilitating pictures of L. tenuis; to two reviewers that helped to improve the manuscript considerably.

\section{References}

Altamirano, A., Salas, C., Yaitul, V., Smith-Ramírez, C., Ávila, A. 2013. Influencia en la heterogeneidad del paisaje en la ocurrencia de incendios australes en Chile. Revista de Geografía Norte Grande, 55, $157-170$.

Arias, E. T., Richardson, B. J. Elgueta, M. 2008. The canopy beetle faunas of Gondwanan element trees in Chilean temperate rain forests. Journal of Biogeography, 35 (5), 914-925. https://doi.org/10.1111/j.13652699.2007.01837.x

Beirne, C., Burdekin, O., Withworth, A. 2013. Herpetofaunal responses to anthropogenic change within a small forest reserve in Eastern Ecuador. Herpetological Journal, 23, 209-219.

Bergallo, H. G., Rocha, C. F. D. 1994. Spatial and trophic differentiation in two sympatric lizards (Tropidurus torquatus and Cnemidophorus ocellifer) with different foraging tactics. Australian Journal of Zoology, 19, $72-75$.

Bond, W. J., Keeley, J. E. 2005. Fire as a global "herbivore": the ecology and evolution of flammable ecosystems. Trends in Ecology and Evolution, 20, 387-394.

Bradstock, R. A., Cohn, J. S. 2002. Fire regimes and biodiversity in semi-arid mallee ecosystems. In: R. A. Bradstock, J. E. Williams \& A. M. Gill, eds. Flammable Australia: the fire regimes and biodiversity of a co ntinent. Cambridge University Press, Cambridge, UK, 238-258.

CONAF. 2014. Plan de manejo RN China Muerta. Technical report. Temuco, Chile, 1-90.

CONAF. 2015. Informe final: Incendio forestal - China Muerta 2015. Technical Report. Temuco, Chile, $1-38$.

Dellasala, D. A., Hanson, C. T. 2015. The ecological importance of mixed-severity fires. Elsevier, Netherlands, $1-450$.

Donoso-Barros, R. 1966. Reptiles de Chile. Ediciones Universidad de Chile, Santiago de Chile, 1-458.

Elgueta, M. 1993. Invertebrados asociados a suelo en bosque de Nothofagus pumilio (OPEP. Et Endl.). Kraser, XII Región-Chile, con especial referencia a Insecta. Revista Chilena de Entomología, 20, 49-60.

Ferreira, D., Mateus, C., Santos, X. 2016. Responses of reptiles to fire in transition zones are mediated by bioregion affinity to species. Biodiversity and Conservation, 25, 1543-1557. https://doi.org/10.1007/ s10531-016-1137-3

Fletcher, M., Moreno, P. I. 2012. Vegetation, climate and fire regime changes in the Andean region of southern Chile $\left(38^{\circ} \mathrm{S}\right)$ covaried with centennial-scale climate anomalies in the tropical Pacific over the last 1500 years. Quaternary Science Reviews, 46, 46-56. https://doi.org/10.1016/j.quascirev.2012.04.016

Holm, S. 1979. A simple sequentially rejective multiple test procedure. Scandinavian Journal of Statistics, 6 (1), 65-70. 10.2307/4615733

Hurtubia, J. 1973. Trophic diversity measurement in sympatric predatory species. Ecology, 54 (6), 885-890. https://doi.org/10.2307/1935684

Hutchenson, K. 1970. A test for comparing diversities based on Shannon formula. Journal of Theoretical Biology, 29 (1), 151-154.

Jaksic, F. 2000. Ecología de comunidades. Ediciones Universidad Católica de Chile, Santiago, 1-233.

Jaksic, F. M., Medel, R. 1987. El acuchillamiento de datos como obtención de intervalos de confianza y pruebas de hipótesis para índices ecológicos. Medio Ambiente, 8, 95-103.

Köeppen, W. 1948. Climatología. Con un estudio de los climas de la tierra. Fondo de Cultura Económica, México, 1-496.

Labra, A., Pienaar, J., Hansen, T. F. 2009. Evolution of thermal physiology in Liolaemus lizards: adaptation, phylogenetic inertia, and niche tracking. American Naturalist, 174 (2), 204-220. 10.1086/600088

Levins, R. 1968. Evolution in a changing environment. Princeton University Press, New Jersey, 1-120. 
Manzur, I., Fuentes, E. R. 1979. Polygyny and agonistic behavior in the tree-dwelling lizard Liolaemus tenuis (Iguanidae). Behavioral Ecology and Sociobiology, 6 (1), 23-28. https://doi.org/10.1007/BF00293241

Maynard, R. S., Aall, N. C., Saenz, D., Hamilton, P. S., Kwiatkowski, M. A.. 2016. Road-edge effects on herpetofauna in a lowland Amazonian rainforest. Tropical Conservation Science, 9 (1), 264-290. https://doi. org/10.1177/194008291600900114

Medel, R. G., Marquet, P. A., Jaksic, F. M. 1988. Microhabitat shifts under different contexts of sympatry: a case study with South American Liolaemus. Oecologia, 76 (4), 567-569. 10.1007/BF00397871

Mora, M., Labra, A. 2017. The response of two Liolaemus species to ash from fire and volcanism. Journal of Herpetology, 51 (3), 388-395. 10.1670/16-105

Morin, P. 2011. Community ecology. Wiley-Blackwell, Sussex, 1-407.

Nimmo, D. L., Telly, L. T., Spence-Bailey, L. M., Watson, S. J., Haslem, A., White, J. G., Clarke, M. F., Bennett, A. F. 2012. Predicting the century-long post-fire responses of reptiles. Global Ecology and Biogeography, 21 (11), 1062-1073. https://doi.org/10.1111/j.1466-8238.2011.00747.x

Ortiz, J. C. 1974. Reptiles del Parque Nacional "Vicente Pérez Rosales". Anales del Museo de Historia Natural de Valparaíso, 7, 317-326.

Pelegrin, N., Bucher, E. H. 2010. Long-term effects of a wildfire on a lizard assemblage in the Arid Chaco forest. Journal of Arid Environments, 74, 368-372. https://doi.org/10.1016/j.jaridenv.2009.09.009

Pianka, E. R. 1973. The structure of lizard communities. Annual Review of Ecology and Systematics, 4, 53-74. https://doi.org/10.1146/annurev.es.04.110173.000413

Pianka, E. R., Witt, L. J. 2003. Lizards: windows to the evolution of diversity. University of Columbia Press, Berkeley, 1-346.

Pickett, S. T. A., White, P. S. 1985. The ecology of natural disturbance and patch dynamics. Academic Press, Orlando, 1-472.

Pincheira-Donoso, D., Núñez, H. 2005. Las especies chilenas del género Liolaemus Weigmann, 1834 (Iguania: Tropiduridae: Liolaeminae): taxonomía, sistemática y evolución. Publicaciones Ocasionales Museo de Historia Natural (Chile), 59, 1-486.

Quinn, G. P., Keough, M. J. 2002. Data design and data analysis for biologists. Cambridge University Press, New York, 1-557.

Ramírez-Bautista, A., Cruz-Elizalde, R. 2013. Reptile community structure in two fragments of cloud forest of the Sierra Madre Oriental, Mexico. North-Western Journal of Zoology, 9 (2), 410-417.

Schulte, J. A., Losos, J. B., Cruz, F. B. Núñez, H. 2004. The relationship between morphology, escape behavior and microhabitat occupation in the lizard clade Liolaemus (Iguanidae: Tropiduridae: Liolaemini). Journal of Evolutionary Biology, 17 (2), 408-420. https://doi.org/10.1046/j.1420-9101.2003.00659.x

Seibold, S., Bässler, C., Baldrian, P., Reinhard, L., Thorn, S., Ulyshen, M. D., Weiss, I., Müller, J. 2016. Deadwood addition promotes non-saproxylic epigeal arthropods but effects are mediated by canopy openness. Biological Conservation, 204, 181-188. https://doi.org/10.1016/j.biocon.2016.09.031

Shannon, C. 1948. A mathematical theory of communication. The Bell System Technical Journal, 27, 379-423.

Simbotwe, M. P. 1984. Resource partitioning in a woodland reptile community of the Kafue flats, Zambia. African Journal of Ecology, 22 (4), 281-287. https://doi.org/10.1111/j.1365-2028.1984.tb00702.x

Sokal, R. R., Rohlf, F. J. 1995. Biometry. W. H. Freeman and Company, New York, 1-887.

Sutton, W. B., Wang, Y., Schweitzer, C. J., Steen, D. A. 2014. Lizard microhabitat and microclimate relationships in Southeastern Pine-Hardwood forest managed with prescribed burning and thinning. Forest Science, 60 (1), 180-190. 10.5849/forsci.11-076

Tulli, M. J., Abdala, V., Cruz, F. B. 2011. Relationships among morphology, clinging performance and habitat use in Liolaemini lizards. Journal of Evolutionary Biology, 24 (4), 843-855.

Uetz, P., Freed, P., Hoŝek. 2020. The Reptile Database. http://www.reptile-database.org. Accesed (May 21, 2020).

Uribe, S. V., Estades, C. 2014. Reptiles in Monterey pine plantations of the Coastal Range of Central Chile. Revista Chilena de Historia Natural, 87, 1-8. http://dx.doi.org/10.1186/S40693-014-0025-Z

Wikars, L.-O. 2002. Dependence of fire in wood-living insects: an experiment with burned and unburned spruce and birch logs. Journal of Insect Conservation, 6, 1-12. https://doi.org/10.1023/A:1015734630309

Willson, M. F., Smith-Ramírez, C., Sabag, C., Hernández, J. F. 1995. Mutualismos entre plantas y animales en bosques templados de Chile. In: Armesto, J. J., Villagrán, C., Arroyo, M. K., eds. Ecología de los bosques nativos de Chile. Editorial Universitaria, Santiago, Chile, 251-264.

Willson, M. F., Sabag, C., Figueroa, J., Armesto, J. J., Caviedes, M. 1996. Seed dispersal by lizards in Chilean rainforest. Revista Chilena de Historia Natural, 69, 339-342.

Woinarski, J. C. Z., Brock, C., Fisher, A., Milne, D., Oliver, B. 1999. Response of birds and reptiles to fire regimes on pastoral land in the Victoria River District, Northern Territory. The Rangeland Journal, 21 (1), 24-38. https://doi.org/10.1071/RJ9990024

Urrutia-Estrada, J., Fuentes-Ramírez, A., Hauenstein, E. 2018. Differences in floristic composition of Araucaria-Nothofagus forests affected by mixed levels of fire severity. Gayana Botanica, 75, 625-638. http://dx.doi. org/10.4067/S0717-66432018000200625 
Zúñiga, A. H., Fuenzalida, V., Sandoval, R. 2016. Uso del espacio por lagartijas simpátridas del género Liolaemus (Squamata, Liolaemidae) en un hábitat fragmentado del sur de Chile. Boletín Chileno de Herpetología, 3, 1-3.

Zúñiga, A. H., Rau, J. R., Fuenzalida, V., Fuentes-Ramírez, A. 2020. Temporal changes in the diet of two sympatric carnivorous mammals in a protected area of south-central Chile affected by a mixed-severity forest fire. Animal Biodiversity and Conservation 43, 177-186. https://doi.org/10.32800/abc.2020.43.0177

Received 20 July 2020

Accepted 25 August 2020 